ENCYCLOPEEDIE Encyclopédie berbère

BERBERE

9 | 1991

9 | Baal - Ben Yasla

\title{
Ben Barakat 'Ali
}

(Ou-Barka 'Ali)

\section{A. Peyron}

\section{OpenEdition}

\section{Journals}

Édition électronique

URL : http://journals.openedition.org/encyclopedieberbere/1665

DOI : 10.4000/encyclopedieberbere. 1665

ISSN : 2262-7197

\section{Éditeur}

Peeters Publishers

\section{Édition imprimée}

Date de publication : 1 avril 1991

Pagination : 1434-1435

ISBN : 2-85744-509-1

ISSN : $1015-7344$

\section{Référence électronique}

A. Peyron, «Ben Barakat 'Ali », Encyclopédie berbère [En ligne], $9 \mid$ 1991, document B56, mis en ligne le

01 avril 2013, consulté le 24 septembre 2020. URL : http://journals.openedition.org/

encyclopedieberbere/1665; DOI : https://doi.org/10.4000/encyclopedieberbere.1665

Ce document a été généré automatiquement le 24 septembre 2020.

(c) Tous droits réservés 


\title{
Ben Barakat 'Ali
}

\author{
(Ou-Barka 'Ali)
}

\section{A. Peyron}

1 'Ali Ben Barakat, ou 'Ali Ou-Barka sous sa forme berbère, est un personnage historique, bien que quelque peu énigmatique. C'est surtout par le biais de l'hagiographie locale que l'on a pu réunir les quelques documents dont on dispose à son sujet (Drouin, 1975). Caïd makhzen des Ayt Yoummour sous Moulay Ismaïl, 'Ali Ou-Barka fit peser l'influence du pouvoir central de façon déterminante sur le pays des imaziyen à une époque où, entre la fin des Dilaïtes et l'émergence des Imhiwaš, la pression des Sanhaja se faisait plus forte.

2 Ennasiri $(1906,107)$ le premier fait état d'un 'Ali Ben Barakat Elyoummouri envoyé à Tinteyalin à la tête de contingents Ayt Idrassen et Ayt Yoummour, avec ordre de tenir cette position-clef lors de la campagne menée par Moulay Ismaïl contre les Ayt Oumalou, les Ayt Yafelman, et les Ayt Serri (Ayt Isri) du Jbel Faazaz en 1693. A la fin de ces opérations, 'Ali Ou-Barka fut l'un des caïds chargés de réunir les têtes des rebelles berbères et de les apporter au sultan dans sa forteresse d'Adekh-san. Il semble avoir été confirmé alors par le souverain dans son commandement à Tounfit et à Aybala. La fondation de cette dernière localité lui est, du reste, parfois attribuée, ainsi que la construction d'une kasbah de garde ('Ksiret Ou-Barka') sur une colline au sud-est de Tounfit qui commande les cluses de l'Ansegmir (Peyron, 1984, 122).

3 Son caïdat des Ayt Yoummour, qui dura environ 35 années, devait lui permettre, tant bien que mal, de contenir la tribu indisciplinée dont il avait la charge. Sa mission consistait essentiellement à limiter l'expansion vers le Nord des Ayt Yahya et autres Ayt Sukhman. Si la plupart des Ayt Yoummour sous ses ordres l'épaulait dans cette tâche, il est clair que d'autres prenaient parfois fait et cause pour leurs frères de la montagne dont ils facilitaient la poussée vers le Tadla (De la Chapelle, 1931, 51). Sans doute ces éléments frondeurs lui reprochaient-ils sa sévérité à leur égard, de même que l'ardeur qu'il déployait à défendre les intérêts du makhzen.

4 Soucieux de faire régner l'ordre, sans pour autant négliger la diplomatie, Ou-Barka se rendit à la Zawiya de Tamgrout, dans le Dra', afin de gagner les bonnes grâces du très influent cheikh Ahmed Bennasser, dont le secours pourrait s'avérer utile lors de ses 
démêlées avec les tribus. Il lui concéda, du reste, un terrain dans le Tadla où fut par la suite édifiée Zawiya ech-Cheikh (De la Chapelle, 1931, 49).

On ne possède guère d'autres détails sur sa vie, à part le fait qu'il se maria peu de temps avant sa mort, et qu'à cette occasion il réunit une telle quantité de dattes, que celles-ci formèrent une colline. Ce serait l'origine du toponyme Tawrirt n-Tini («colline des dattes ») à proximité d'une de ses résidences, à la limite est du pays Ayt Sukhman.

6 La tradition orale est plus loquace à propos de sa mort, bien que les versions divergent. Vers la fin du règne de Moulay Ismaïl, la situation étant compliquée par des intrigues dynastiques, l'agitation dans le Maroc central atteignit son comble. Ou-Barka fut finalement assassiné par ses propres neveux, les Ouled 'Aïcha Termoun " pour dégager les Ayt Yoummour du joug du makhzen» (De la Chapelle, 1931, 51); pour laver l'honneur familial suite à la violation par leur caïd d'un pacte de protection (Drouin, 1975, 39). Ceci venait s'ajouter aux nombreuses exactions commises par ce dignitaire qui, manifestement, était devenu bien embarrassant pour la tribu. Représenté négativement par l'oralité comme teigneux et comme oppresseur, son meurtre eut lieu vraisemblablement du côté d'El Herri, entre Tinte-faim et Khenifra, vers 1727-1730. Une autre source précise Tit n-Teslit, non loin de Tounfit, comme lieu du drame (Drouin, 1975, 50), ce qui est également plausible.

7 Sans doute 'Ali Ou-Barka représentait-il une manifestation de plus de ce pouvoir personnel laïque, qui allait connaître encore de nombreux émules sur la scène marocaine au cours des trois siècles à venir. En effet, chaque fois que des conflits internes émiettaient le tissu social de ces tribus, lesquelles semblaient malgré tout tendre vers une certaine démocratie (Guennoun, 1933, 168) étaient alors réunies les conditions propices à l'apparition des féodaux d'une envergure plus ou moins grande, et qui manquaient rarement de se réclamer d'une caution makhzénienne.

\section{BIBLIOGRAPHIE}

CHAPELLE F. de la, « Le Sultan Moulay Ismaïl et les Berbères Sanhaja du Maroc central », in Arch. Mar., vol. XXVIII, Champion, Paris, 1931.

DROUIN J., Un cycle oral hagiographique dans le Moyen-Atlas marocain, Sorbonne, Paris, 1975, p. 38-52.

ENNASIRI A., Kitab Elistiqsa (trad. E. Fumey) in Arch. Mar., vol. IX, Leroux, Paris, 1906.

GUENNOUN S., La montagne berbère, Omnia, Rabat, 1933.

PEYRON M., « Contribution à l'histoire du Haut Atlas oriental : les Ayt Yafelman », in R.O.M.M., 38/2, Aix-en-Provence, 1984, p. 117-135.

INDEX

Mots-clés : Biographie, Maroc 